\title{
45 degree arrangement of compact array antenna for MIMO application
}

\author{
M. F. Ismail' ${ }^{1}$, H. A. Majid², C. Macwright ${ }^{3}$, M. N. A. H Shaabani ${ }^{4}$, M. S. Mohd ${ }^{5}$, M. M. Zahar ${ }^{6}$, \\ F. Zubir ${ }^{7}$, O. Ayob $^{8}$, M. A. Abdullah' ${ }^{9}$ \\ ${ }^{1,4,5,6}$ Centre for Diploma Studies, Universiti Tun Hussein Onn Malaysia, Malaysia \\ ${ }^{2,3}$ Faculty of Engineering Technology, Universiti Tun Hussein Onn Malaysia, Malaysia \\ ${ }^{7,8}$ Faculty of Engineering, Universiti Teknologi Malaysia, Malaysia \\ ${ }^{9}$ Agensi Angkasa Malaysia
}

\section{Article Info \\ Article history: \\ Received Oct 1, 2018 \\ Revised Feb 10, 2019 \\ Accepted Feb 25, 2019}

Keywords:

MIMO antenna

Mutual coupling

\begin{abstract}
A study on the compact array microstrip patch antenna for multiple-input multiple-output (MIMO) communication system based on the antenna arrangement is performed. The $2.45 \mathrm{GHz}$ rectangular array are arranged in 45 degree slanted inward and outward for each other to reduce the mutual coupling effect between the patches. The antenna properties are analyzed and compact antenna design is determined based on the simulation results. The results show the antennas can very compact while maintaining low mutual coupling. The gain of the MIMO antenna is $11.3 \mathrm{dBi}$. The simulated and tested return losses, together with the radiation patterns, are presented and discussed.
\end{abstract}

\section{Corresponding Author:}

Muhammad Faizal bin Ismail,

Centre for Diploma Studies,

Universiti Tun Hussein Onn Malaysia,

84600 Pagoh, Johor, Malaysia.

Email: ifaizal@uthm.edu.my

\section{INTRODUCTION}

In telecommunication system, the data rate is a key aspect for the performance analysis. In a condition which the modulation and the frequencies can't be altered, the data rate still can be increased by multiplying the data path. MIMO offers higher data capacity than the capacity of the single-input-singleoutput (SISO) antenna system [1]. The single antenna configuration normally has a wider antenna radiation pattern while the multiple antenna has more directive radiation. MIMO antenna was robust against channel fading and interferences. The MIMO allowing a faster data rate through the antenna by allowing the data to travel in multiple path through spatial multiplexing [2]. Without using the multiplexing technique, the additional antenna would not increase the data speed as the additional antennas only increase the diversity order but do not provide independent communication channels [3]. The are several research conduction on MIMO antenna [4-10].

This project focused on the antenna technology develop using a low cost patch antenna design. The antenna would be used in point to point communication. In rising need for fast internet access for an organization, the point to point communication seems to be the best possible solution to connect the user with the data server. Point to point communication is based on line of sight communication over a certain distances depending on the frequency band. Any obstacle in its wave propagation path would create a disturbance which degrade its performance. As it only involves single receiver and single transmitter antenna, it usually utilizes an antenna with high gain as it would provide a narrow radiation pattern beam [11-13]. 
As the content getting more interactive and increase in resolution, the data size sent over in the data link getting larger. Together with high number of user, these would create a slow data traffic for the normal antenna with low bandwidth. Antenna with Multiple Input Multiple Output (MIMO) offer a high bandwidth and at the same time providing a high speed connection [14-15]. However antenna using the MIMO architecture usually large in size has a greater wind resistance once it mounted in high rise building. However the multiple antenna array design produce a mutual coupling effect that reduce the antenna performance.

\section{ANTENNA DESIGN}

Figure 1 and Table 1 shows the proposed antenna dimensions The antenna was designed using FR4 substrate board with thickness of $1.6 \mathrm{~mm}$, dielectric constant of 4.5 and tangential loss of 0.019. The FR4 board has low water absorption making it suitable for outdoor usage. The low coefficient of thermal expansion of the FR4 allow the antenna to be manufactured using the wet etching technique with thermal as catalyst.

The antenna patch size, "C" and "D" decrease slightly each time the number of antenna element increase. The decreased of antenna size is done to counter balance the effect of the antenna on the effective radiation. The frequency of the antenna increases each time the number of the antenna increased. This causing the antenna S11 and S21 to shift toward the higher frequency. To maintain the effective frequency of $2.4 \mathrm{GHz}$, the antenna patch size was decreased.

The value "K" was predetermine using a parametric studies. The V-shape antenna placement has a gap of $0.8 \mathrm{~mm}$, away from the other antennas. The antenna " $E$ " value was determine using the parametric study conducted for the "K" value. The gap "E" was slightly larger to for allow space for the antenna transmission lines marked in " $F$ ". The thickness of " $\mathrm{H}$ " is calculated for equal distribution of the transmitted power to the antenna patch. The transmission lines marked by " $\mathrm{H}$ " is the power divider of the antenna. The antenna port is raised towards the antenna element marked by "J" to allow two antennas SMA jack port to be soldered and connected to the RF cable.
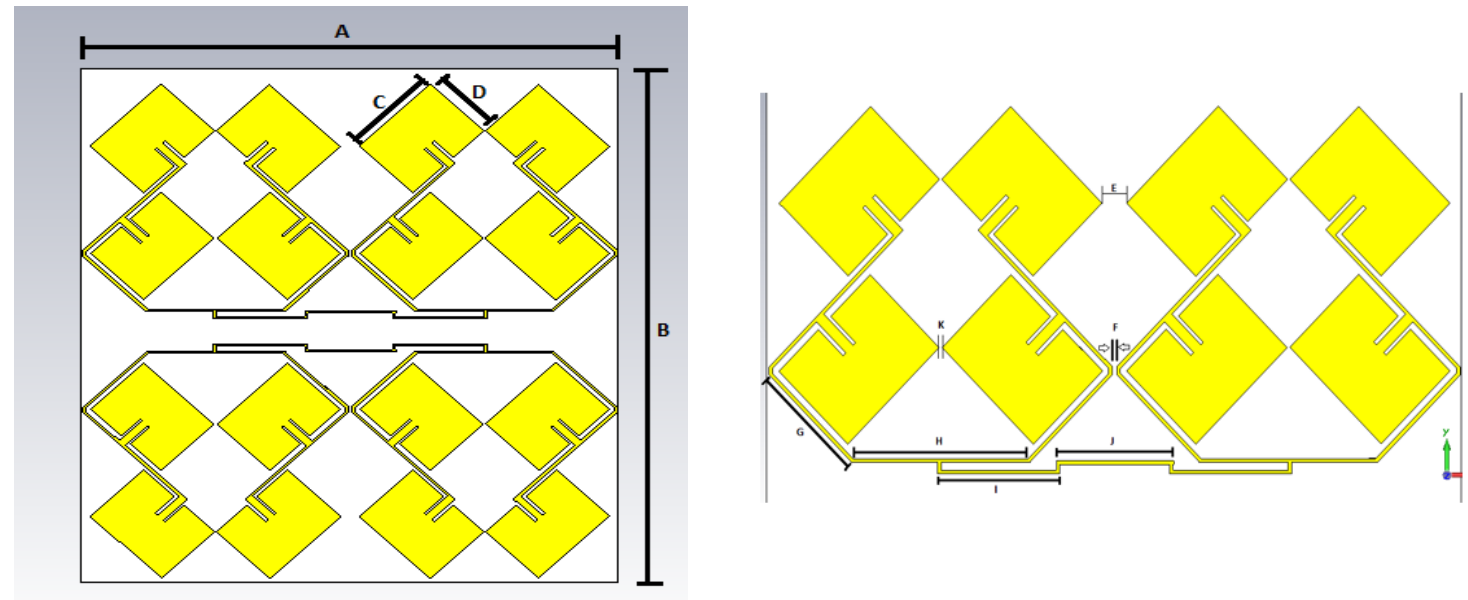

Figure 1. General dimension of the antenna

Table 1. The geometry specifications of the proposed antenna

\begin{tabular}{cc}
\hline Variable & Dimension $(\mathrm{mm})$ \\
\hline A & 198 \\
B & 210 \\
C & 37 \\
D & 28 \\
E & 7.00 \\
F & 1.36 \\
G & 33.4 \\
H & 50.00 \\
I & 35.00 \\
J & 33.70 \\
K & 0.80 \\
\hline
\end{tabular}




\section{RESULTS AND ANALYSIS}

The fabricated antenna as shown in Figure 2 has undergone a simulation and testing using CST simulation and tested inside the anechoic chamber. The S-parameter of the antenna was plotted in a single graph shown in Figure 3. The tested antenna has the lowest antenna return loss $\mathrm{S} 11$, at $2.45 \mathrm{GHz}$ with the value of $-35.32 \mathrm{~dB}$ and a mutual coupling is at the at $2.45 \mathrm{GHz}$ with the value of $-46.81 \mathrm{~dB}$. For simulation result, the antenna has the highest radiating efficiency at the $2.45 \mathrm{GHz}$ with antenna return loss, $\mathrm{S} 11$ has the value of $-15.15 \mathrm{~dB}$ and antenna mutual coupling, $\mathrm{S} 21$ is at $-28.34 \mathrm{~dB}$.

Simulated antenna has narrow bandwidth for $2.4 \mathrm{GHz}$ channel. It has $\mathrm{S} 11$ value ranges from $-7.1 \mathrm{~dB}$ to $-5.8 \mathrm{~dB}$ at frequency from $2.4 \mathrm{GHz}$ to $2.5 \mathrm{GHz}$ with its highest value at $2.45 \mathrm{GHz}$. The tested antenna bandwidth $2.4 \mathrm{GHz}$ to $2.5 \mathrm{GHz}$ with the $\mathrm{S} 11$ value at $2.4 \mathrm{GHz}$ is $-11.6 \mathrm{~dB}$. At $2.5 \mathrm{GHz}$, the antenna $\mathrm{S} 11$ value is at $-14.21 \mathrm{~dB}$. For the $\mathrm{S} 21$ value, the antenna has the value of $-37.46 \mathrm{~dB}$ at $2.4 \mathrm{GHz}$ and value of $-24.10 \mathrm{~dB}$ at $2.5 \mathrm{GHz}$.

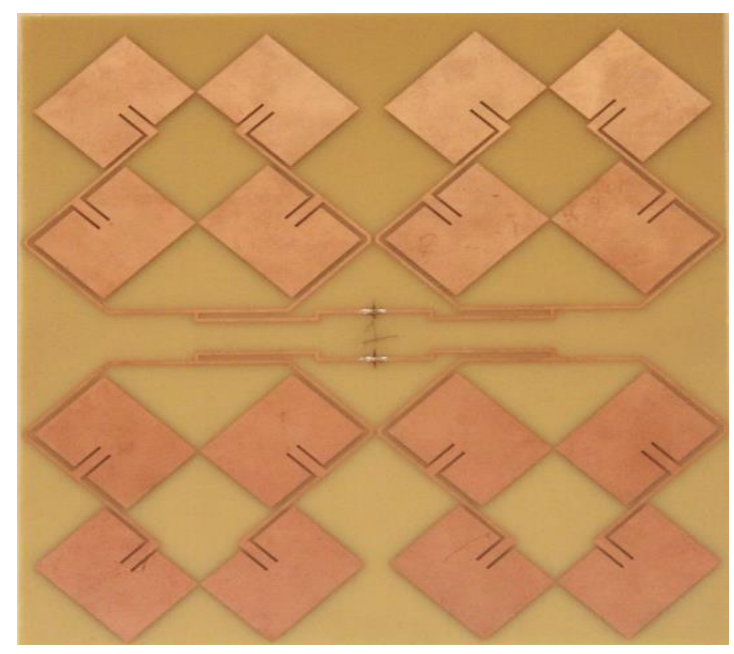

Figure 2. Fabricated antenna

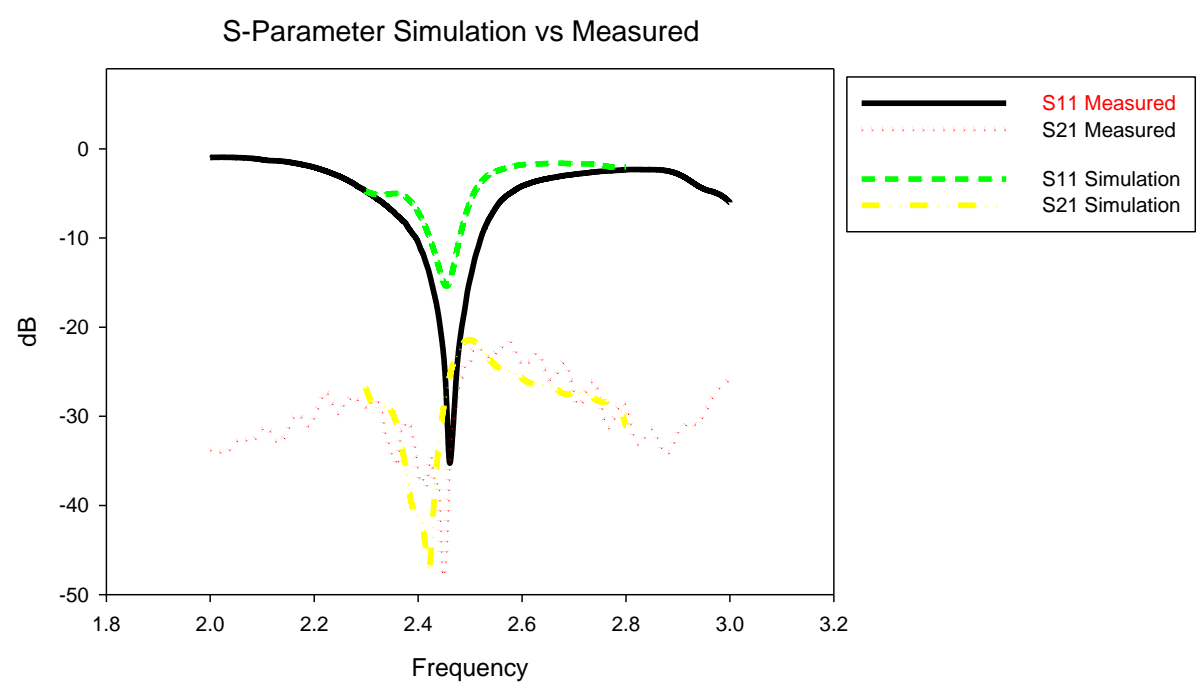

Figure 3. Measured and simulated S-parameter of proposed antenna

Antenna radiation pattern shows the antenna has a directive radiation pattern with the antenna gain of $11.3 \mathrm{~dB}$ in the simulation shown in Figure 4. The tested antenna has the radiation pattern has the radiation pattern on $7.19 \mathrm{~dB}$. The radiation was almost at 0 degree at plane. The antenna has the gain of $4.69 \mathrm{~dB}$ when place at 45 degree angle as the antenna is polarize. The 3-dimensional radiation pattern are shown in 
Figure 5. It has narrow radiation pattern with almost no side lobe. The antenna has a $7.19 \mathrm{~dB}$ gain measured because the physical shape of the antenna has change. During manufacturing, the antenna has flex toward the radiation port. The concave shape of the antenna has diverge the antenna array lowering the antenna gain.

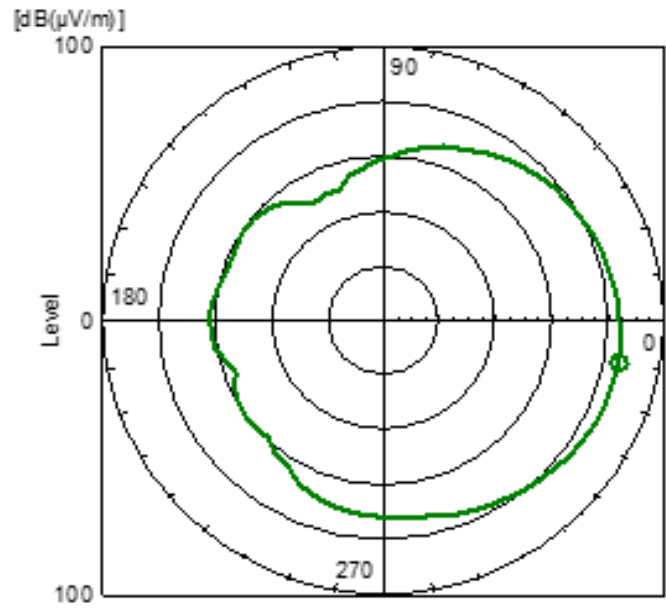

(a)

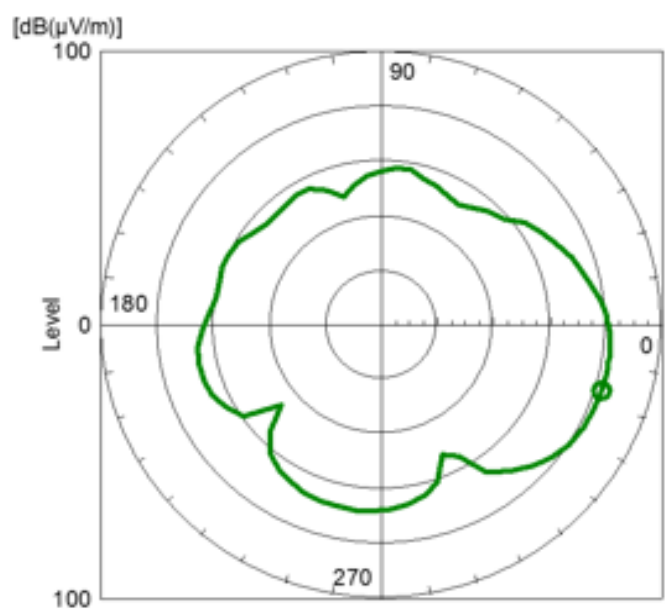

(b)

Figure 4. Radiation of the antenna at (a) H-plane, (b) E-plane

\begin{tabular}{|ll|}
\hline Type & Farfield \\
\hline Approximation & enabled $(k R>>1)$ \\
Monitor & farfield $(f=2.4)[1]$ \\
Component & Abs $[1]$ \\
Output & Directivity \\
Frequency & 2.4 \\
Rad. effic. & $-2.839 \mathrm{~dB}$ \\
Tot. effic. & $-3.774 \mathrm{~dB}$ \\
Dir. & $11.35 \mathrm{dBi}$ \\
\hline
\end{tabular}

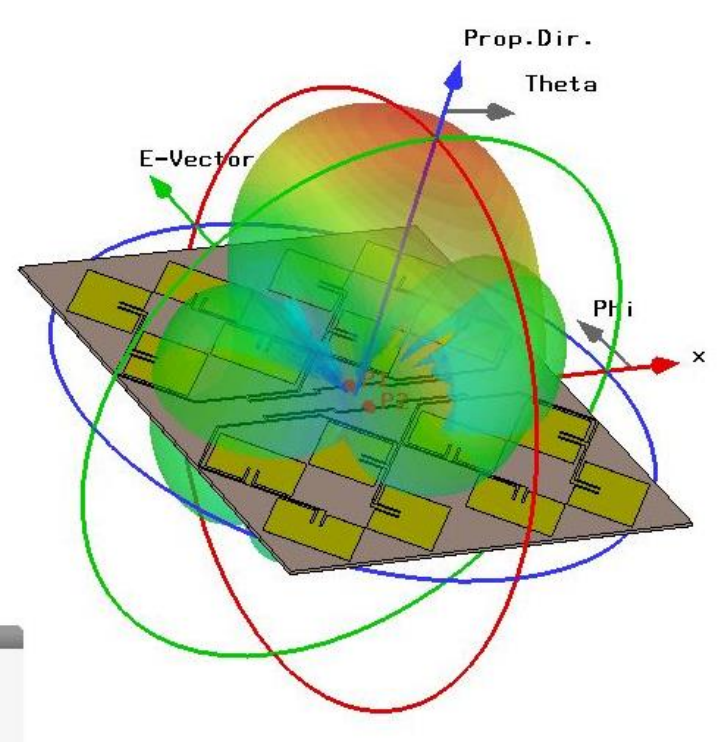

Figure 5. 3-dimensional radiation pattern

The prototype antenna has a few of its limitation. The first limitation are about the bandwidth. At bandwidth of $2.4 \mathrm{GHz}$ band, the antenna has the antenna return loss of $-11.6 \mathrm{~dB}$ at $2.4 \mathrm{GHz}$ and $-14.21 \mathrm{~dB}$ at $2.5 \mathrm{GHz}$. For the antenna to operate with it maximum efficiency, the antenna must be using the frequency of $2.45 \mathrm{GHz}$. The second antenna weakness, the antenna is non-dual band type antenna. This limit the antenna usage to only $2.4 \mathrm{GHz}$ frequency band. In some cases where the $5.8 \mathrm{GHz}$ frequency band is more favor, the prototype antenna cannot be utilize. The prototype antenna has limited antenna gain. The non-planar type antenna has a high antenna gain up to $30 \mathrm{dBi}$. This enable the antenna to be use in long range point to point communication. At $7.19 \mathrm{~dB}$, the antenna range is limited for medium range communication only. 


\section{CONCLUSION}

In this project, the microstrip patch antenna was design for point to point communication system that utilize the non-planar type antenna design system. Using the Mikrotik RouterBox BaseBox2, the antenna can transmit and received a signal wave with high data throughput. The antenna design using the MIMO principle allow the antenna to gain higher gain compare to the normal single antenna design up to $11.3 \mathrm{dBi}$ simulated and $7.19 \mathrm{~dB}$ actual tested. The high antenna gain allow the antenna to has more directive radiation pattern (angular degree of 34.8 degree) and can reach further compared to low gain antenna operating using the same high frequency as the MIMO type antenna. The antenna was design to be in slanted position to polarise the antenna element so that it can be placed closed together up to $1 \mathrm{~mm}$. As the antenna was develop and manufactured using wet etching technique, the antenna separation need to be limit to $1 \mathrm{~mm}$ to give the antenna etching some tolerance during manufacturing process. V shaped antenna placement for antenna has the $\mathrm{S} 11$ value of $12 \mathrm{dBi}$ and $\mathrm{S} 21$ value of $27 \mathrm{dBi}$ at $2.45 \mathrm{GHz}$ in simulation and $-35.32 \mathrm{~dB} \mathrm{~S} 11$ and $-46.81 \mathrm{~dB}$ S21 actual tested. Both a of the S21 and S11 value allow the antenna to be placed closer in the final design which has the $\mathrm{S} 21$ and $\mathrm{S} 11$ value of $28 \mathrm{dBi}$ and $15 \mathrm{dBi}$. This translate into antenna gain of $11.3 \mathrm{dBi}$ simulated and $7.19 \mathrm{~dB}$ actual.

For the future works, the antenna can be increase it performance and compactness by using a higher grade of material. The higher grade of material that has higher dielectric constant would further decrease the individual antenna sizes. The antenna also need a holding plate that hold the FR4 board firmly. The antenna also need to improve its bandwidth.

\section{ACKNOWLEDGEMENTS}

Thanks to the Ministry of Education (MOE), Universiti Tun Hussein Onn Malaysia (UTHM) and Universiti Teknologi Malaysia (UTM) for supporting the research work under grant no U544, U923, FRGS 1614 (UTHM) and 16H08 (UTM).

\section{REFERENCES}

[1] H. Wang, et al., "A Compact Wideband Quad Element Planar Antenna for WiMAX MIMO Application," IEEE, pp. 4799-3540, 2014.

[2] A. Ahmed and D. Grace, "Dual-Hop Backhaul Network Architecture for 5G Ultra Small Cell Using Milimeter Wave," IEEE, pp. 4673-6555, 2015.

[3] A. F. Molisch, et al., "Capacity of MIMO System with Antenna Selection," IEEE Transaction on Wireless Communication, vol. 4, Jul 2005.

[4] M. A. Matin and A. I. Sayyed, "A Design Rule for Inset-fed Rectangular Microstrip Patch Antenna," WSEAS Transaction on Communication. IEEE, pp. 1109-2742, Jan 2010.

[5] M. N. Osman, et al., "Compact Dual-Port Polarization-Reconfigurable Antenna with High Isolations for MIMO Application," IEEE Antennas and Wireless Propagation Letters, vol. 15, 2016.

[6] M. N. Osman, et al., "Dual-port polarization reconfigurable antenna using compact CPW slotline feeding structure for space-limited MIMO application," 2015 IEEE Conference on Antenna Measurements \& Applications (CAMA), 2015

[7] Y. Peng, et al., "Error Resilient Video Transmission for Short Range Point to Point Wireless Communication," IEEE, pp. 4244-7116, 2010.

[8] A. M. Tulino, et al., "Impact of Antenna Correlation on the Capacity of Multiantenna Channels," vol. 51, Jul 2005.

[9] M. A. Afridi, "Mcrostrip Patch Antenna- Designing at 2.4GHz Frequency," Science Signpost Publishing. Biological and Chemical Research, pp.128-132, 2015.

[10] I. Berenguer and X. Wang, "MIMO Antenna Selection with Lattice Reduction Aided Linear Reciever," IEE Transaction on Vehicular Technology, vol. 53, Sep 2004.

[11] D. W. Bliss, et al., "MIMO Wireless Communication," Lincoln Labrotary Journal, pp. 97-126, 2006.

[12] Kadir, et al., "MIMO Beamforming Network Having Polarization Diversity," 3rd European Conference on Antennas and Propagation, pp. 1743-1747, 2009.

[13] M. R. Andrews, et al., "Tripling the capacity of wireless communications using electromagnetic polarization," Nature, vol. 409, pp. 316-318, Jan 2001.

[14] Q. H. Spencer, et al., "Zero-Forcing Methods for Downlink Spatial Multiplexing in Multiuser MIMO Channels," IEEE Transactions on Signal Processing, vol. 52, Feb 2004.

[15] D. W. Browne, et al., "Experiments with compact antenna arrays for MIMO radio communications," IEEE Trans. Antennas Propag., vol. 54, pp. 3239-3250, Nov 2006. 


\section{BIOGRAPHIES OF AUTHORS}
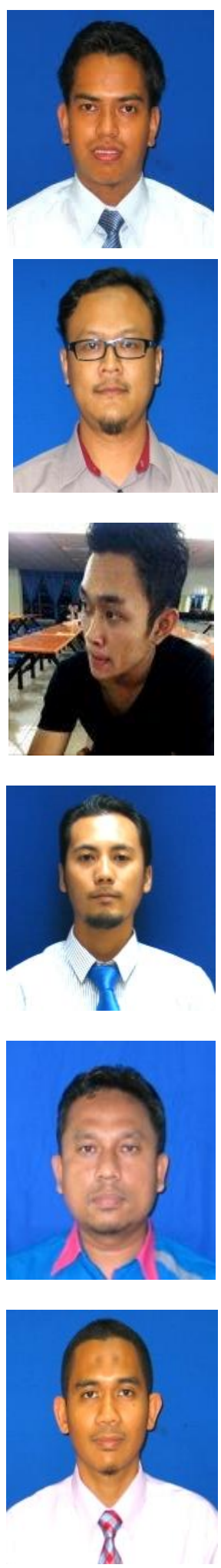

Muhammad Faizal Ismail received the Bachelor of Electrical Engineering (Telecommunications) with honours and M.Eng (Electrical Engineering) from Universiti Teknologi Malaysia, in 2009 and 2011 respectively. He is currently a lecturer at the Department of Electrical Engineering, Centre for Diploma Studies, Universiti Tun Hussein Onn Malaysia. His research interest includes the areas of design of electromagnetic band gap (EBG) structure, microstrip antenna and pattern reconfigurable EBGs antenna. He has published many conference proceedings as well as journal papers in local and international journals.

Huda A Majid received the B Eng. degree in Electrical Engineering (Telecommunication) from Universiti Teknologi Malaysia, in 2007. He then obtained his M.Eng in 2010 and PhD degrees in Electrical Engineering in 2013, at Universiti Teknologi Malaysia. He is currently a lecturer in the Department of Electrical Engineering Technology, Faculty of Engineering Technology, Universiti Tun Hussein Onn Malaysia. His research interest includes the areas of design of microstrip antennas, small antennas, Reconfigurable antennas, metamaterials structure, metalaterial antennas and millimeter wave antennas. He has published over 100 articles in journals and conference papers.

Thomas, Charles MacWright received his Bachelor Degree in Electrical Engineering Tecnology (Computer and Communication) from Universiti Tun Hussein Onn Malaysia (UTHM) in 2017. His research interests is in antenna designs.

Mohd Nurul Al-Hafiz bin Sha'abani received the Bachelor of Mechatronic Engineering (with honours) and MSc. degree in Electrical Engineering from Universiti Teknikal Malaysia Melaka in 2010 and 2014, respectively. He was engaged in industry in the fields of system integration and embedded system. He is currently with Universiti Tun Hussein Onn Malaysia as a lecturer. His research interest includes the design and development of intelligent systems, robotics and biomedical engineering.

Mohd Sabani Bin Mohd received the B Eng. degree in Electrical, Electronic and System Engineering with honours from Universiti Kebangsaan Malaysia, in 1996. He had experiend in Indutrial about 16 years before joint Universiti Tun Hussien Onn Malaysia in 2013. His research interest includes the areas of analogue and electronic.

Mohd Muzaffar Zahar received his B. Eng. in Electrical Engineering (Mechatronics) with honours from Universiti Teknologi Malaysia in 2008. He also graduated in same university with a M. Eng. (Electrical Engineering) in 2013. Begin in education system since 2010 at Industrial Training Institute of Marang, then at Advanced Training Centre (ADTEC) of Melaka, next in National Youth High Skill Training Institutes of Pagoh and now as lecturer in Universiti Tun Hussein Onn Malaysia (UTHM). Based on his experienced in different institution, the research interest includes routing in wireless sensor network, industrial automation and application of control engineering. 

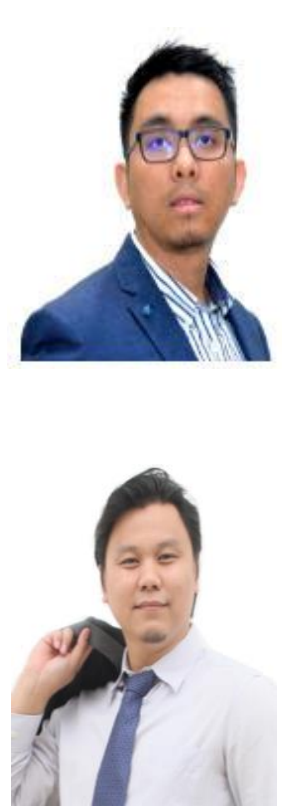

Farid Zubir (M'10) received the B.Eng. degree in Electrical majoring in Telecommunication as well as M.Eng. (RF \& Microwave) degree from the Universiti Teknologi Malaysia (UTM) in 2008 and 2010 respectively. In 2015, he then obtained his Ph.D degree from the University of Birmingham, UK, for research into direct integration of power amplifiers with antennas in microwave transmitters. He is currently serves as a Senior Lecturer in the Department of Communication Engineering, School of Electrical Engineering, UTM. His current research interest and specialization are in the area of RF and microwave technologies including planar array antenna, dielectric resonator antenna (DRA), active integrated antenna (AIA), microstrip reflectarray antenna (MRA), millimetre wave antenna, electromagnetic band gap (EBG), artificial magnetic conductor (AMC), metamaterial and microwave power amplifiers. He has published over 40 articles in journals, book chapters, conference papers and proceedings.

Osman Ayop received his Ph.D in Electrical Engineering (2016), M.Eng. (RF \& Microwave) (2010) and B.Eng. in Electrical majoring in Telecommunication (2007) degree from the Universiti Teknologi Malaysia (UTM). In 2013, He was also done his attachment in Uppsala University of Sweden under the supervision of Prof. Dr Vernon Cooray. He is currently serves as a Senior Lecturer in the Department of Communication Engineering, School of Electrical Engineering, UTM. His current research interest and specialization are in the field of antennas (Microstrip antenna, planar array antenna, ultra-wideband antenna and dielectric resonator antenna), propagation, and also metamaterials (electromagnetic band gap, left-handed, absorber, and artificial magnetic conductor). He has been published numerous of journals, proceedings, research books, and book chapters. He also won several university and national awards related to his research works. He has been appointed as a reviewer for several national/international journals and conferences. He is also an active researcher in Advanced RF and Antenna Research Group (ARFMRG) and has been participated in a lot of courses, seminars, exhibition etc.

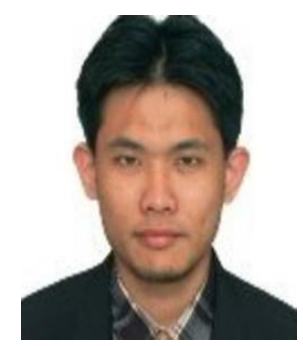

Muhammad Azfar bin Abdullah received the Bachelor of Electrical Engineering (Telecommunications) with honours and M.Eng (Electrical Engineering) from Universiti Teknologi Malaysia, in 2010 and 2014 respectively. He is currently work as a researcher at National Space Agency Malaysia. His research interest includes the areas of design of electromagnetic band gap (EBG) structure, microstrip antenna. He has published many conference proceedings as well as journal papers in local and international journals. 